\title{
Theoretical Insights into the Mechanism of Wavelength Regulation in Blue-Absorbing Proteorhodopsin
}

\author{
Choongkeun Lee ${ }^{1}$, Sivakumar Sekharan ${ }^{2}$, and Blake Mertz ${ }^{1,3}$
}

${ }^{1}$ C. Eugene Bennett Department of Chemistry, West Virginia University, Morgantown, WV

${ }^{2}$ XtalPi Inc, One Broadway, Cambridge, MA 02142, USA

${ }^{3}$ WVU Cancer Institute, West Virginia University, Morgantown, WV

Corresponding author: blake.mertz@mail.wvu.edu

This PDF file includes:

Figs. S1 to S4

Tables S1 to S4 
Table S1: Distances of key interactions within retinal binding pocket based on QM/MM calculations.

\begin{tabular}{|c|c|c|c|c|c|c|c|c|c|c|}
\hline \multirow{3}{*}{ Interaction } & \multirow{3}{*}{ X-ray ${ }^{\mathrm{a}}$} & \multicolumn{9}{|c|}{$\mathrm{QM} / \mathrm{MM}$ optimized models } \\
\hline & & \multicolumn{3}{|c|}{1} & \multicolumn{3}{|c|}{ II } & \multicolumn{3}{|c|}{ III } \\
\hline & & 1 & 2 & 3 & 1 & 2 & 3 & 1 & 2 & 3 \\
\hline $\mathrm{N}_{\mathrm{SB}} \cdots \mathrm{D} 97$ & 4.29 & 4.71 & 4.84 & 4.61 & 4.79 & 4.84 & 4.63 & 4.85 & 4.89 & 4.58 \\
\hline $\mathrm{N}_{\mathrm{SB}} \cdots \mathrm{D} 227$ & 3.18 & 3.83 & 3.71 & 3.92 & 3.55 & 3.69 & 3.89 & 3.78 & 4.24 & 3.94 \\
\hline $\mathrm{N}_{\mathrm{SB}} \cdots \mathrm{Q} 105$ & 5.15 & 3.83 & 4.02 & 3.91 & 6.36 & 4.29 & 5.28 & - & - & - \\
\hline 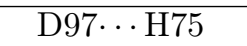 & 2.67 & 2.75 & 2.71 & 2.70 & 2.76 & 2.72 & 2.71 & 2.74 & 2.73 & 2.70 \\
\hline 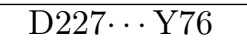 & 2.53 & 2.66 & 4.22 & 2.79 & 2.66 & 2.68 & 2.79 & 2.66 & 2.68 & 2.79 \\
\hline $\mathrm{R} 94 \cdots \mathrm{D} 227$ & 2.94 & 4.63 & 4.97 & 4.94 & 4.79 & 5.03 & 4.87 & 4.70 & 5.37 & 4.87 \\
\hline 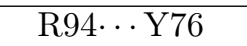 & 3.17 & 2.88 & 3.00 & 3.13 & 2.94 & 3.05 & 3.11 & 2.90 & 3.29 & 3.07 \\
\hline Q105‥C15 & 4.06 & 3.39 & 3.63 & 3.49 & 5.93 & 3.86 & 4.99 & - & - & - \\
\hline $\mathrm{O}_{\epsilon}(\mathrm{Q} 105) \cdots \mathrm{H}_{\mathrm{a}}$ & - & 2.40 & 2.65 & 2.47 & 5.02 & 2.85 & 4.01 & - & - & - \\
\hline $\mathrm{C}-\mathrm{O}_{\mathrm{a}}(\mathrm{D} 97)$ & 1.25 & 1.25 & 1.27 & 1.27 & 1.25 & 1.27 & 1.27 & 1.25 & 1.27 & 1.27 \\
\hline $\mathrm{C}-\mathrm{O}_{\mathrm{b}}(\mathrm{D} 97)$ & 1.24 & 1.27 & 1.25 & 1.25 & 1.27 & 1.25 & 1.25 & 1.27 & 1.25 & 1.25 \\
\hline $\mathrm{C}-\mathrm{O}_{\mathrm{c}}(\mathrm{D} 227)$ & 1.25 & 1.28 & 1.29 & 1.30 & 1.28 & 1.29 & 1.30 & 1.27 & 1.19 & 1.30 \\
\hline $\mathrm{C}-\mathrm{O}_{\mathrm{d}}(\mathrm{D} 227)$ & 1.25 & 1.25 & 1.23 & 1.23 & 1.25 & 1.23 & 1.23 & 1.25 & 1.23 & 1.23 \\
\hline RMSD / $\AA$ & - & 0.87 & 1.13 & 0.94 & 0.87 & 0.90 & 0.80 & - & - & - \\
\hline
\end{tabular}

${ }^{\mathrm{a} X-r a y ~ s t r u c t u r e ~(P D B ~ 4 J Q 6) \cdot[1] ~}$

Table S2: Bond lengths of the conjugated portion of retinal from QM/MM calculations.

\begin{tabular}{c|c|c|c|c|c|c|c|c|c|c|c}
\multirow{2}{*}{ Model } & \multirow{2}{*}{ Ret. Only } & \multirow{2}{*}{ JIHFAH $^{b}$} & \multicolumn{3}{|c|}{$\mathrm{I}$} & \multicolumn{3}{|c|}{ II } & \multicolumn{2}{c}{ III } \\
\cline { 5 - 12 } & & & 1 & 2 & 3 & 1 & 2 & 3 & 1 & 2 & 3 \\
\hline BLA $^{c}$ & 0.0383 & 0.0824 & 0.0806 & 0.0850 & 0.0849 & 0.0808 & 0.0840 & 0.0819 & 0.0790 & 0.0810 & 0.0806 \\
\hline $\mathrm{C} 5=\mathrm{C} 6$ & 1.38 & 1.35 & 1.37 & 1.37 & 1.37 & 1.37 & 1.37 & 1.37 & 1.37 & 1.37 & 1.37 \\
\hline $\mathrm{C} 6-\mathrm{C} 7$ & 1.45 & 1.46 & 1.46 & 1.46 & 1.46 & 1.46 & 1.46 & 1.46 & 1.46 & 1.47 & 1.46 \\
\hline $\mathrm{C} 7=\mathrm{C} 8$ & 1.37 & 1.34 & 1.36 & 1.36 & 1.36 & 1.36 & 1.36 & 1.36 & 1.36 & 1.36 & 1.36 \\
\hline $\mathrm{C} 8-\mathrm{C} 9$ & 1.43 & 1.45 & 1.45 & 1.45 & 1.45 & 1.45 & 1.45 & 1.45 & 1.45 & 1.45 & 1.45 \\
\hline $\mathrm{C} 9=\mathrm{C} 10$ & 1.39 & 1.35 & 1.37 & 1.37 & 1.37 & 1.37 & 1.37 & 1.37 & 1.37 & 1.37 & 1.37 \\
\hline $\mathrm{C} 10-\mathrm{C} 11$ & 1.41 & 1.43 & 1.43 & 1.43 & 1.43 & 1.43 & 1.43 & 1.43 & 1.43 & 1.43 & 1.43 \\
\hline $\mathrm{C} 11=\mathrm{C} 12$ & 1.39 & 1.36 & 1.36 & 1.36 & 1.37 & 1.36 & 1.37 & 1.37 & 1.37 & 1.37 & 1.37 \\
\hline $\mathrm{C} 12-\mathrm{C} 13$ & 1.41 & 1.42 & 1.43 & 1.44 & 1.44 & 1.44 & 1.44 & 1.44 & 1.43 & 1.43 & 1.44 \\
\hline $\mathrm{C} 13=\mathrm{C} 14$ & 1.41 & 1.37 & 1.38 & 1.37 & 1.37 & 1.38 & 1.38 & 1.38 & 1.38 & 1.38 & 1.38 \\
\hline $\mathrm{C} 14-\mathrm{C} 15$ & 1.39 & 1.40 & 1.42 & 1.43 & 1.43 & 1.42 & 1.43 & 1.43 & 1.42 & 1.43 & 1.43 \\
\hline $\mathrm{H}_{a}-\mathrm{C} 15$ & 1.09 & - & 1.09 & 1.09 & 1.09 & 1.08 & 1.09 & 1.09 & 1.09 & 1.09 & 1.09 \\
\hline $\mathrm{H}_{b}-\mathrm{N}_{S B} B$ & 1.02 & - & 1.08 & 1.10 & 1.09 & 1.07 & 1.11 & 1.10 & 1.07 & 1.10 & 1.10
\end{tabular}

${ }^{\text {a } O p t i m i z e d ~ i n ~ g a s ~ p h a s e ~ a t ~ B 3 L Y P / 6-31 G(d) ~ u s i n g ~ G a u s s i a n 09 . ~}$

${ }^{b}$ X-ray structure of N-Methyl-N-phenylretinal iminium perchlorate (Refcode: JIHFAH) from the CSD. Note that the SB nitrogen atom is attached to an aromatic ring and perchlorate ion is present near the $\beta$-ionone ring.

${ }^{\mathrm{c}}$ Bond length alternation (in $\AA$ ) along retinal polyene chain computed by Eq. (3). 
Table S3: Dihedral angle measurements of polyene chain of retinal from QM/MM calculations.

\begin{tabular}{|c|c|c|c|c|c|c|c|c|c|c|c|c|}
\hline \multirow{2}{*}{ Model } & \multirow{2}{*}{ Crystal $^{\mathrm{a}}$} & \multirow{2}{*}{ RetGP } & \multirow{2}{*}{$\operatorname{RetCSD}^{\mathrm{c}}$} & \multicolumn{3}{|c|}{ I } & \multicolumn{3}{|c|}{ II } & \multicolumn{3}{|c|}{ III } \\
\hline & & & & 1 & 2 & 3 & 1 & 2 & 3 & 1 & 2 & 3 \\
\hline $\mathrm{TAD}^{\mathrm{d}}$ & 2.1 & 1.5 & 3.7 & 5.3 & 5.1 & 5.2 & 5.1 & 5.2 & 5.4 & 4.0 & 5.9 & 5.5 \\
\hline $\mathrm{C} 1-\mathrm{C} 5=\mathrm{C} 6-\mathrm{C} 7$ & 187 & 187.3 & 185.0 & 182.3 & 181.9 & 182.1 & 182.0 & 181.5 & 182.3 & 182.3 & 175.7 & 182.9 \\
\hline $\mathrm{C} 5=\mathrm{C} 6-\mathrm{C} 7=\mathrm{C} 8$ & 170 & 170.3 & 175.8 & 165.0 & 169.7 & 168.7 & 166.1 & 170.0 & 168.1 & 165.9 & 163.3 & 168.7 \\
\hline $\mathrm{C} 6-\mathrm{C} 7=\mathrm{C} 8-\mathrm{C} 9$ & 181 & 181.5 & 182.6 & 181.1 & 180.9 & 182.2 & 177.9 & 180.9 & 182.2 & 179.4 & 175.1 & 183.0 \\
\hline $\mathrm{C} 7=\mathrm{C} 8-\mathrm{C} 9=\mathrm{C} 10$ & 180 & 179.7 & 183.3 & 177.2 & 176.2 & 175.0 & 180.8 & 176.7 & 175.1 & 178.8 & 184.0 & 174.5 \\
\hline $\mathrm{C} 8-\mathrm{C} 9=\mathrm{C} 10-\mathrm{C} 11$ & 180 & 179.8 & 181.3 & 180.6 & 184.1 & 185.8 & 176.5 & 184.9 & 185.4 & 178.7 & 177.3 & 186.1 \\
\hline $\mathrm{C} 9=\mathrm{C} 10-\mathrm{C} 11=\mathrm{C} 12$ & 180 & 180.4 & 183.5 & 187.1 & 182.0 & 184.1 & 189.0 & 182.0 & 185.8 & 187.3 & 184.3 & 184.3 \\
\hline $\mathrm{C} 10-\mathrm{C} 11=\mathrm{C} 12-\mathrm{C} 13$ & 180 & 179.4 & 183.5 & 179.7 & 186.4 & 185.5 & 175.7 & 187.5 & 185.1 & 177.6 & 182.9 & 184.8 \\
\hline $\mathrm{C} 11=\mathrm{C} 12-\mathrm{C} 13=\mathrm{C} 14$ & 180 & 181.1 & 175.6 & 188.0 & 176.0 & 182.6 & 184.6 & 175.8 & 183.5 & 185.9 & 176.2 & 184.1 \\
\hline $\mathrm{C} 12-\mathrm{C} 13=\mathrm{C} 14-\mathrm{C} 15$ & 180 & 179.0 & 184.5 & 179.5 & 191.7 & 187.2 & 180.1 & 190.9 & 187.8 & 179.8 & 190.8 & 186.0 \\
\hline $\mathrm{C} 13=\mathrm{C} 14-\mathrm{C} 15=\mathrm{N}$ & 180 & 180.4 & 175.8 & 194.7 & 176.1 & 184.4 & 174.6 & 175.6 & 182.5 & 183.1 & 175.3 & 184.4 \\
\hline $\mathrm{C} 14-\mathrm{C} 15=\mathrm{N}=\mathrm{C}_{\epsilon}$ & 199 & 179.2 & 179.5 & 176.7 & 184.3 & 184.3 & 187.2 & 184.3 & 184.8 & 183.8 & 184.5 & 185.0 \\
\hline
\end{tabular}

${ }^{a}$ Crystal structure obtained from protein date bank (PDB 4JQ6).[1]

${ }^{\mathrm{b}}$ Optimized in gas phase at B3LYP/6-31G(d) using Gaussian09.

${ }^{\mathrm{c}}$ X-ray structure of N-Methyl-N-phenylretinal iminium perchlorate (Refcode: JIHFAH) from the CSD.

dTorsional angle deviation value is computed using Eq. (4).

Table S4: Comparison of BLA and TAD values between microbial retinal proteins.

\begin{tabular}{c|c|c|c|c|c|c|c|c} 
& BPR $^{\mathrm{a}}$ & $\mathrm{bR}^{\mathrm{b}}$ & halorhodopsin[2] & $\mathrm{XR}^{\mathrm{c}}$ & $\mathrm{ESR}^{\mathrm{d}}$ & $\mathrm{KR}^{\mathrm{e}}$ & $\mathrm{GR}^{\mathrm{f}}$ & OLPVRII $^{\mathrm{g}}$ \\
\hline$\lambda_{\max }(\mathrm{nm})$ & 490 & 568 & 578 & 565 & 534 & 525 & 545 & 515 \\
\hline $\mathrm{BLA}(\AA)^{\mathrm{h}}$ & 0.085 & 0.105 & 0.040 & 0.076 & 0.134 & 0.121 & 0.116 & 0.048 \\
\hline $\mathrm{TAD}\left(^{\circ}\right)^{\mathrm{i}}$ & 5.1 & 5.0 & 7.4 & 0.9 & 6.3 & 4.0 & 15.7 & 3.6
\end{tabular}

apR values obtained from most stable optimized structure of BPR (I.2).

${ }^{b} \mathrm{bR}$ : bacteriorhodopsin. Values obtained from PDB 1C3W.[3]

${ }^{\mathrm{c} X R}$ : xanthorhodopsin. Values obtained from PDB 3DDL.[4]

dESR: E. sibiricum rhodopsin. Values obtained from PDB 4HYJ.[5]

eKR2: light-driven sodium pump KR2. Values obtained from PDB 6REW.[6]

${ }^{\mathrm{f}}$ GR: Gloeobacter rhodopsin. Values obtained from PDB 6NWD.[7]

goLPVRII: Organic Lake Phycodnavirus rhodopsin II. Values obtained from PDB 6SQG.[8]

${ }^{\mathrm{h}}$ Bond length alternation (BLA) along retinal polyene chain obtained using Eq. (3) in main text.

${ }^{\mathrm{i}}$ Torsional angle deviation (TAD) obtained using Eq. (4) in main text. 

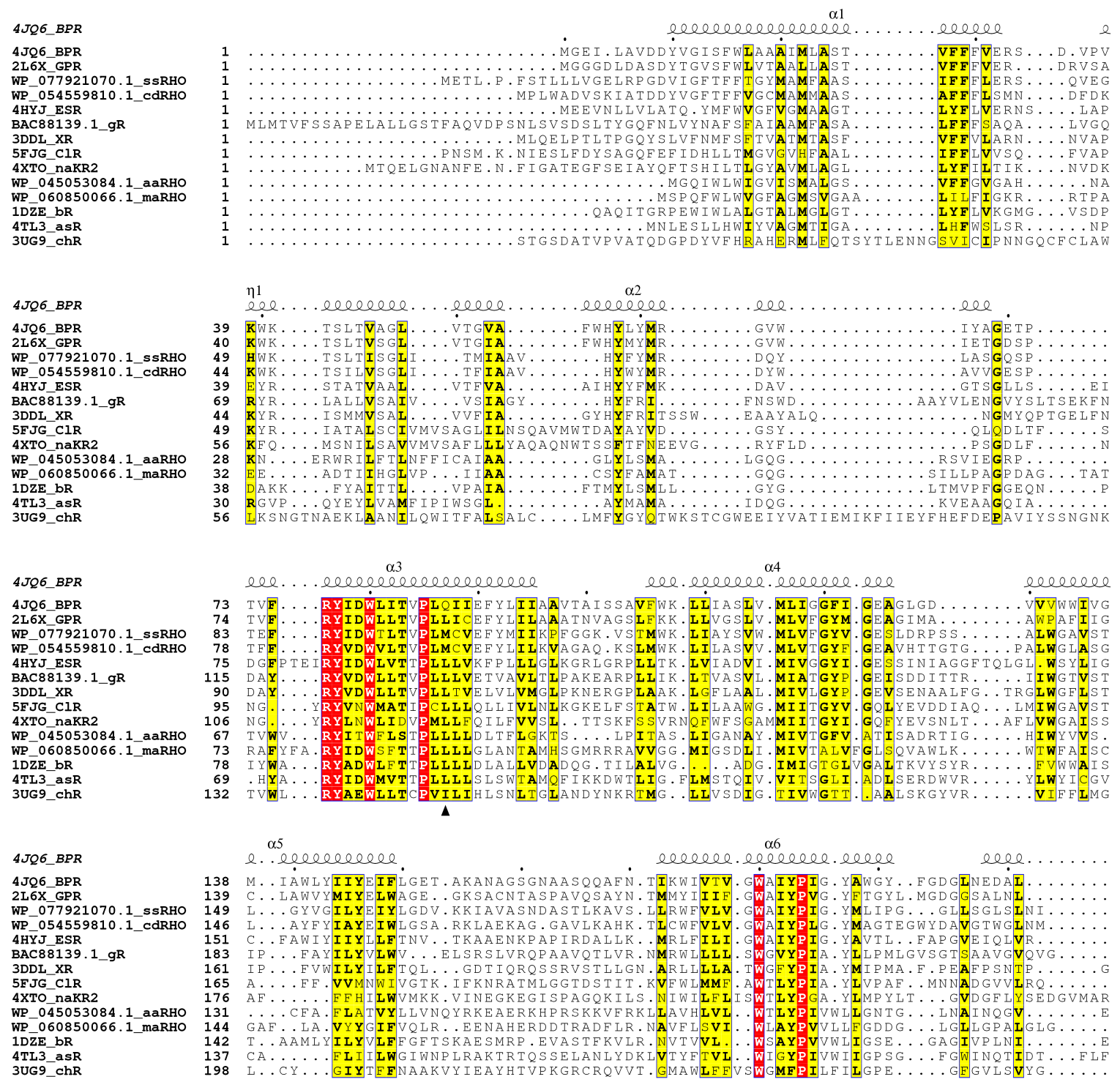

e. 25 eceeceece

$\alpha 6$
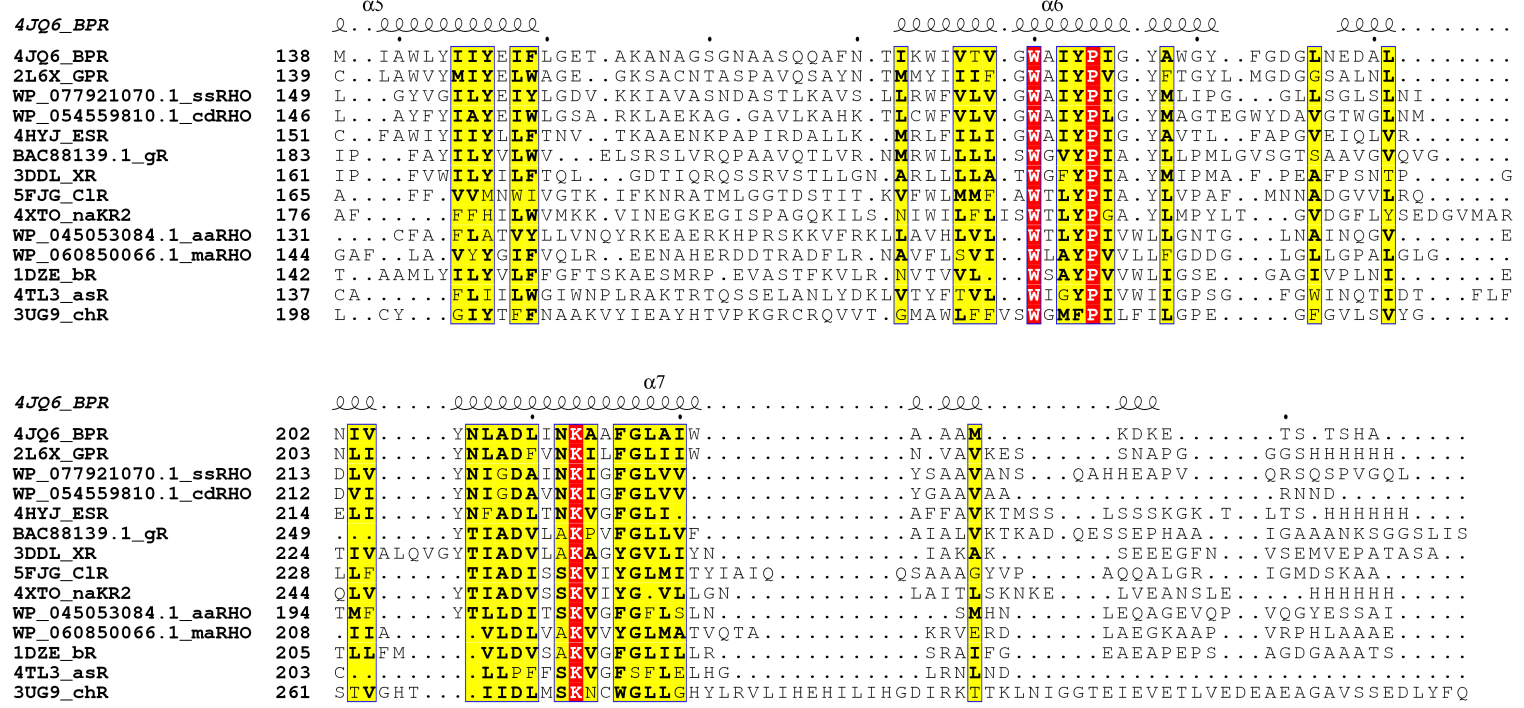

Figure S1. H75 in proteorhodopsin is lacks complete conservation among microbial retinal proteins. Multiple sequence alignment of blue and green PR with other retinal proteins. H75 (second row, position 57 in BPR, 4JQ6_BPR) is conserved with rhodopsins from green PR (2L6X_GPR), Spirosoma sp. 209 (WP_077921070.1_ssRHO), Croceitalea dokdonensis (WP_054559810.1_cdRHO), E. sibiricum rhodopsin (4HYJ_ESR), Gloebacter rhodopsin (BAC88139.1_gR), and xänthorhodopsin (3DDL_XR). 5FJG_ClR: chlo-

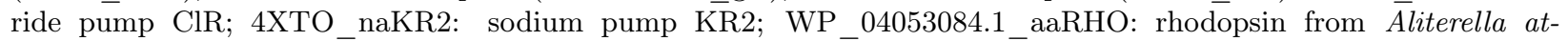
lantica; WP_060850066.1_maRHO: rhodopsin from Methylobacterium aquaticum; 1DZE_bR: bacteriorhodopsin; 4TL3_asR: Anabaena sensory rhodopsin; 3UG9_chR: channelrhodopsin. Top row: secondary structure of BPR (PDB 4JQ6); yellow: partially convserved residues; red: completely conserved residues; arrow: position 105, location of color-tuning switch in PR. Rendering created in ESPript. 

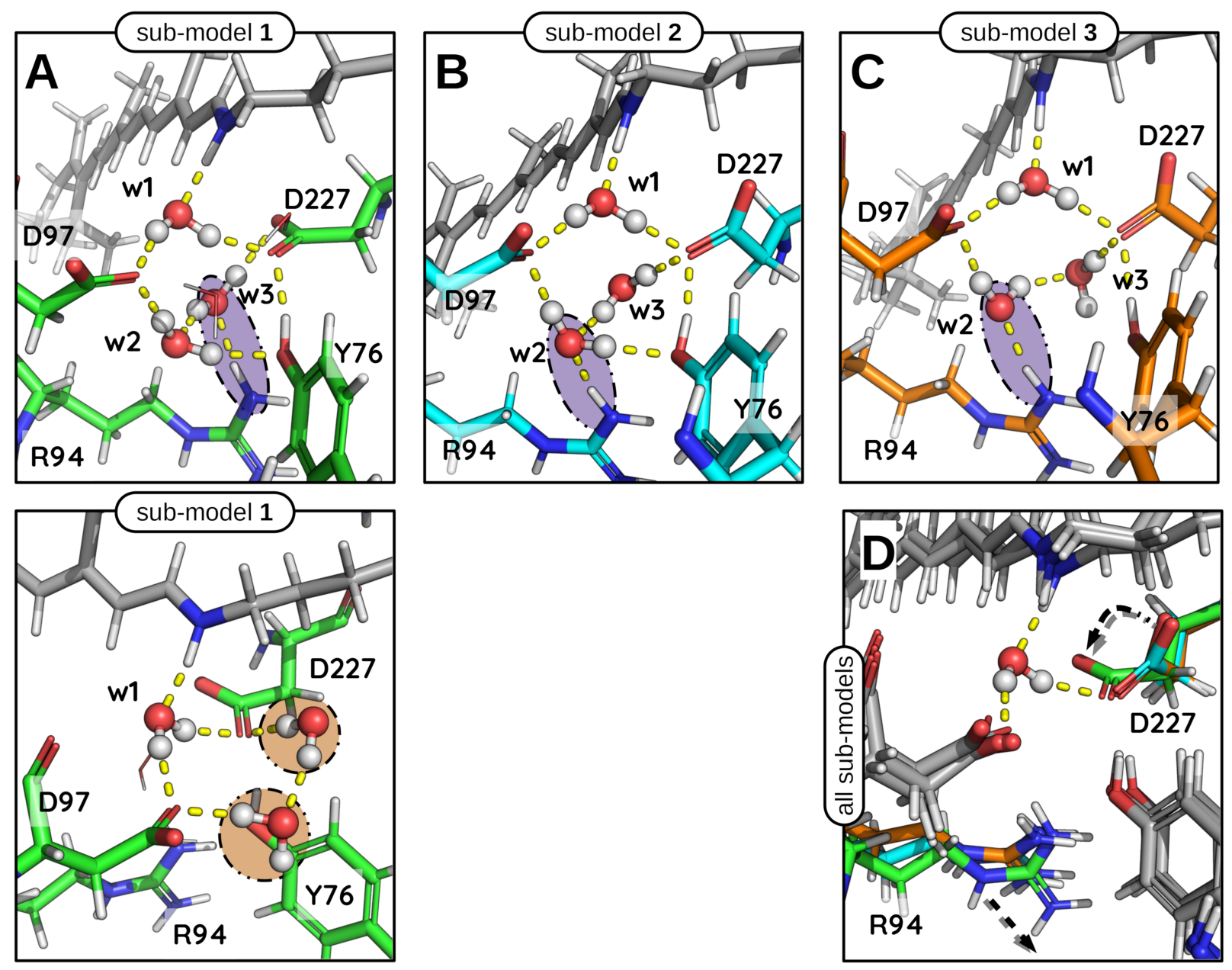

Figure S2. Y76 and R94 play a role in rearrangement of hydrogen-bonded network within the retinal binding pocket of BPR. A) Top: snapshot of first of two pentagonal water clusters in sub-model 1 . w1 forms hydrogen bonds with the retinal Schiff base (SB), D97, and D227, whereas w2 hydrogen bonds to D97, w3, and Y76, and w3 hydrogen bonds to w2 and D227. Bottom: a second pentagonal cluster of waters forms above the plane of the SB, D97, and D227 towards Y76. B) Snapshot of retinal binding pocket in sub-model 2. The water cluster rearranges, leading to a shift in the hydrogen bond with R94 from w3 to w2. w2 maintains its hydrogen bond with Y76 and w3 as well. C) Snapshot of retinal binding pocket in sub-model 3. Note the rotation of w3 away from the SB, allowing w2 to utilize both hydrogens in the pentagonal cluster instead of hydrogen bonding with Y76. D) Superposition of all three sub-models, with w1 from sub-model 1 included to show the hydrogen-bonded network with the retinal chromophore. D227 undergoes a 90-degree rotation along its chi2 dihedral angle and R94 shifts slightly away from the retinal binding pocket in sub-model 1 (green sticks), leading to the rearrangement of the water cluster in the binding pocket. 

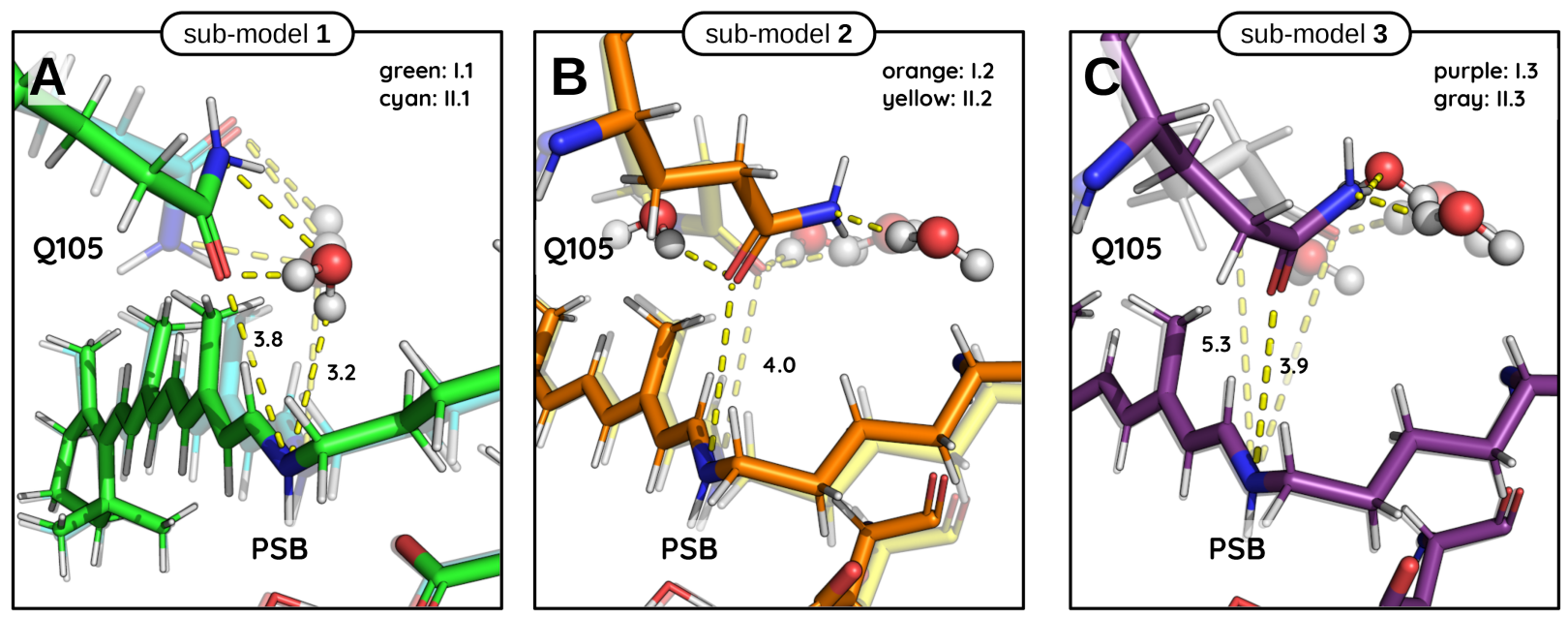

Figure S3. Rotational orientation of the sidechain of Q105 has negligible effect on the spectral absorption wavelength of BPR. A) Overlay of snapshots of the orientation of Q105 in sub-model 1 in Group I (green sticks) and in Group II (semi-transparent cyan sticks). The orientation of the water coordinated with Q105 in Group I $(501 \mathrm{~nm})$ also interacts with the PSB, stabilizing the orientation of the carbonyl oxygen towards the PSB. However, in Group II $(493 \mathrm{~nm})$ the sidechain of Q105 is rotated away from the PSB, in particular the amine group (5.0 $\AA$ away). B) Overlay of snapshots of the orientation of Q105 in sub-model 2 in Group I (orange sticks) and in Group II (semi-transparent yellow sticks). In sub-model 2, two water molecules are coordinated with Q105, stabilizing the orientation of the amino acid sidechain parallel to the plane of the polyene chain (about $4.0 \AA$ away). Group I (496 $\mathrm{nm})$ has the amine group pointed towards K231, whereas in Group II $(505 \mathrm{~nm})$ the terminal group is rotated $180^{\circ}$ towards the $\beta$-ionone ring. C) Overlay of snapshots of the orientation of Q105 in sub-model 3 in Group I (purple sticks) and in Group II (semi-transparent gray sticks). In Group I (499 nm) the carbonyl group in the sidechain of Q105 is oriented towards the PSB, about the same distance as in sub-models 1 and 2, but this time not coordinated with a water molecule. In contrast, the carbonyl in the Q105 sidechain of Group II (500 nm) coordinates both water molecules and the amine group has a very indirect interaction with the PSB (5.3 $\AA$ away).

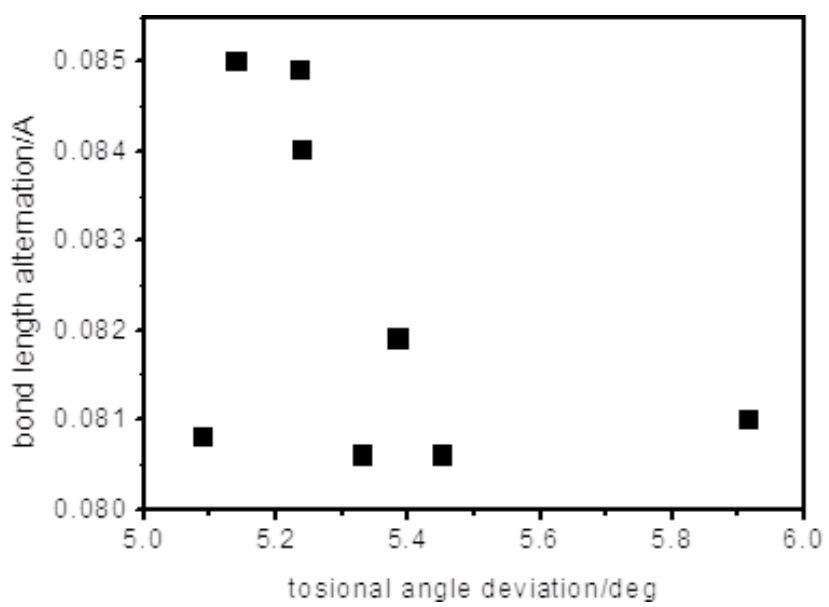

Figure S4. No correlation exists between bond length alternation (BLA) and torsional angle deviation (TAD) in BPR. Plot of BLA versus TAD in QM/MM calculations of BPR. Despite the fact that BLA and TAD display direct or inversely correlated relationships with specific aspects of the retinal binding pocket (distance from Q105, wavelength, hydrogen bond energy, and relative energy of retinal, Figs. 6 and 7), they do not show a direct relationship with one another. 


\section{References}

(1) Ran, T.; Ozorowski, G.; Gao, Y.; Sineshchekov, O. A.; Wang, W.; Spudich, J. L.; Luecke, H. Acta Crystallographica Section D Biological Crystallography 2013, 69, 1965-1980.

(2) Pal, R.; Sekharan, S.; Batista, V. S. Journal of the American Chemical Society 2013, 135, 9624-9627.

(3) Luecke, H.; Schobert, B.; Richter, H.-T.; Cartailler, J.-P.; Lanyi, J. K. Journal of Molecular Biology 1999, 291, 899-911.

(4) Luecke, H.; Schobert, B.; Stagno, J.; Imasheva, E. S.; Wang, J. M.; Balashov, S. P.; Lanyi, J. K. Proceedings of the National Academy of Sciences 2008, 105, 16561-16565.

(5) Gushchin, I.; Chervakov, P.; Kuzmichev, P.; Popov, A. N.; Round, E.; Borshchevskiy, V.; Ishchenko, A.; Petrovskaya, L.; Chupin, V.; Dolgikh, D. A.; Arseniev, A. A.; Kirpichnikov, M.; Gordeliy, V. Proceedings of the National Academy of Sciences 2013, 110, 12631-12636.

(6) Kovalev, K.; Polovinkin, V.; Gushchin, I.; Alekseev, A.; Shevchenko, V.; Borshchevskiy, V.; Astashkin, R.; Balandin, T.; Bratanov, D.; Vaganova, S.; Popov, A.; Chupin, V.; Büldt, G.; Bamberg, E.; Gordeliy, V. Science Advances 2019, 5, eaav2671.

(7) Morizumi, T.; Ou, W.-L.; Eps, N. V.; Inoue, K.; Kandori, H.; Brown, L. S.; Ernst, O. P. Scientific Reports 2019, 9, 1-14.

(8) Bratanov, D. et al. Nature Communications 2019, 10, 4939. 